\title{
New Solidification Materials in Nuclear Waste Management
}

\author{
Neslihan Yanikomer**, Sinan Asal**, Sevilay Haciyakupoglu**, Sema Akyil Erenturk** \\ *Department of Mechanical Engineering, Faculty of Engineering and Architecture, Istanbul Gelisim University, 34315 \\ Avcilar, Istanbul, Turkey. \\ **Energy Institute, Istanbul Technical University, 34469 Maslak, Istanbul, Turkey. \\ (nyanikomer@gelisim.edu.tr, asal@itu.edu.tr, haciyakup1@itu.edu.tr, erenturk@itu.edu.tr)
}

\begin{abstract}
\$Corresponding Author; Neslihan Yanikomer, Department of Mechanical Engineering, Faculty of Engineering and Architecture, Istanbul Gelisim University, 34315 Avcilar, Istanbul, Turkey, Tel: +90 5445989846, nyanikomer@gelisim.edu.tr
\end{abstract}

Received: 27.05.2016 Accepted: 25.06.2016

\begin{abstract}
One of the major worldwide environmental issue is the long-term storage or disposal of nuclear waste. Research in solidification materials for long-term storage of high-level nuclear wastes in nuclear industry has started as an imperative need. During the last decade, new solidification materials have been developed for immobilization of actinides and fission products for geological disposal. The materials used for immobilization generally have relatively complex compositions. The structure of these materials investigates using diffraction and spectroscopic methods. Most of the interest has focused on their chemical durabilities and capacity of waste loading. Their physical and chemical properties should not be degraded by $\alpha$-decay event irradiation from the incorporated actinides. The development of new materials either for storage or for disposal for a long time is still required. In this article, recent developments in the use of solidification materials for the immobilization of high level of nuclear wastes have been reviewed. The comparison of properties of solidification materials is summarized with several applications in connection with experience and technological needs in literature.
\end{abstract}

Keywords: Nuclear energy, nuclear waste, solidification materials, immobilization, long-term storage.

\section{Introduction}

The environmental impact of energy generation can be evaluated on several ways that includes evaluation of type and amount of contaminant produced per unit energy generated by the source, contaminant distribution in atmosphere and environment, effects on occupants and public's health, amount and toxicity of waste and long term effects on environment and ecological systems [1, 2].

Nuclear energy has been used since 1950s in the world. Progress in energy has increased the demand of nuclear power plants and also made it a current issue against global warming in the world. Nuclear industry uses the highest technologies of the world and develops rapidly as a high-tech sector. Even a very good pollution controls, nuclear power plants still generates waste materials. Nuclear industry is accepted one of the rare industries considering its special attention to waste management. Nuclear industry prepares regulations in accordance with laws and monitors the implementation by independent organizations $[1,2]$.
Ionizing radiations from radioactive materials are utilized for diagnose and treatment in medical sector. Radioisotopes are producing in nuclear plants continuously to supply the needs of research, industry and medical sectors. Radioactive sources or materials are managed as radioactive waste; therefore, they are isolated carefully for every usage.

After one-year operation of a 1000 MW light water reactor, the obtained spent fuel without reprocessing is approximately 30 tonnes consisting of $95.6 \%$ uranium, $1 \%$ plutonium, $0.1 \%$ transuranium isotopes (plutonium, neptunium etc.) and $3.3 \%$ fission products (cesium, strontium, iodine etc.). After separating uranium and plutonium for reuse, the percentage of fission products in reprocessed spent fuel (proximately 1 ton) is $93.3 \%$. Fission products loss $98 \%$ of their radioactivities within 200 years. For this reason, storage of fission products in radioactive waste by solidification is very important. There are many radionuclides as fission products in the waste. Cesium and strontium are the most important radionuclides in fission products. Despite ${ }^{137} \mathrm{Cs}$ has 30.2 and ${ }^{134} \mathrm{Cs} 2.1$ years of physical half-life, their biological and whole body half-life 
are almost 40 days. Thereby, it seems that in terms of radiological point of view, ${ }^{137} \mathrm{Cs}$ is the most important radionuclide produced in a nuclear process. ${ }^{90} \mathrm{Sr}$ radionuclide has long physical ( $\mathrm{t}_{1 / 2}: 28.60$ years) and biological half-life and dispersion of ${ }^{90} \mathrm{Sr}$ to the environment causes damages to human body by incorporation into bones and teeth due to its high energetic beta particles $\left(\mathrm{E}_{\beta}: 546 \mathrm{keV}\right)$ [3-8].

Immobilization of high level radioactive waste by a way that will not harm to human and environment is an important subject. Despite scientific authorities do not accept as a problem to nuclear wastes requiring a new immobilization technology, public perception for nuclear wastes is seriously problem to threat life and environment comparison with other industrial wastes $[1,3,9]$.

The development of nuclear power industry brings back the responsibility to address the issue of nuclear wastes in stable solid forms for interim storage or disposition in geologic repositories. The solidification of nuclear wastes has been an active and booming research area for over 50 years. The aim of this review is to contribute literature by providing an overview including important developments and methods about immobilization of high-level radioactive waste with the help of researches executed so far and to make some interpretations and recommendations for the optimization and selection of solidification materials for the applications.

\section{Storage by Solidification of Nuclear Wastes}

High level nuclear waste have buried to deep underground repositories in specifically chosen geological formations. Further studies on nuclear waste storage are continuing in the world. Geological and environmental factors like groundwater movement, structure of rock, erosion, flood, earthquake, volcanic activities, natural resources and population etc. are important factors regarding disposal site selection [10-14].

Considering that the only mechanism to leak radioactivity from underground repositories to biosphere is groundwater movement, repositories constructed in geological formations have to select far from groundwater. It is clarified that geological formations like granite, basalt, salt and tuff have proper specifications for a waste repository. Considering fossil fuel-fired power plants, nuclear power plants produce less waste and own better protection procedures for the wastes. The nuclear wastes are stored in heavy concrete containers that are placed in deep boreholes or caverns excavated deep underground and monitored continuously. Some waste packages are shown in Figure 1. The containers have ability to retain radionuclides over $\sim 100000$ years in fact the nuclear wastes become safe in 300-500 years [1014].

Immobilisation of radioactive wastes in relatively inert solid matrices before storage is advantageous for safety and economic reasons. Practically the most common method is pouring concrete around waste in containers. Liquid wastes are occasionally used as part of concrete mixture but the durability of final product is relatively weak. The long-term trend of radionuclides moves upward to the surface of the solid material. Cementation and vitrification techniques are the most preferable methods for solidification of nuclear wastes [10-13].
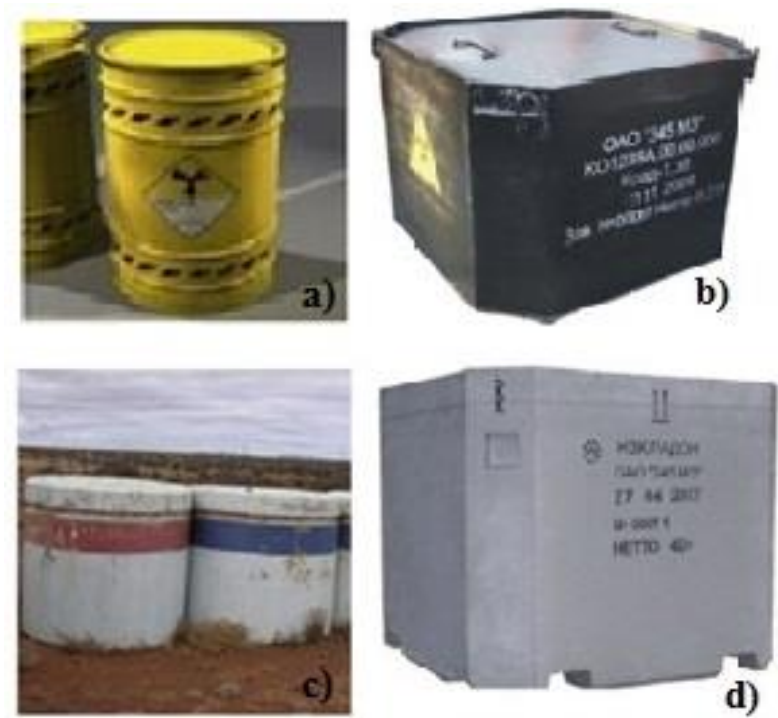

Fig. 1. Waste packages in use: a) drum, b) metal box, c) concrete cylinder d) concrete container [13]

Depending on the classification of nuclear waste, different solidification material uses for immobilization of radioactive waste. Figure 2 shows immobilization techniques related to radioactivity levels in waste [13].

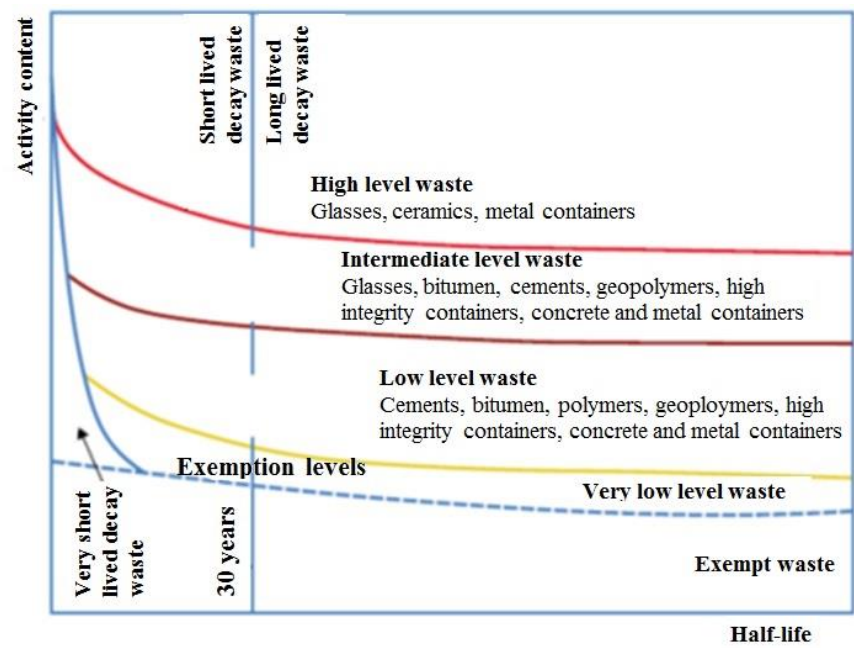

Fig. 2. Typical materials used for nuclear waste conditioning (reproduced from [13])

Selection of a solidification form depends on the physical and chemical nature of the radioactive waste and the acceptance criteria for the storage and disposal facilities. The key considerations on selecting an immobilising material are [12]:

Chemical durability is one of the most important properties in waste forms. Chemical durability of waste forms can be determined with several methods. The leach rate in $\mathrm{g} \mathrm{m}^{-2} \mathrm{~d}^{-1}$ is given by;

$$
L=\frac{A_{i}}{\left(A_{0} \times S \times t\right)}
$$


where $A_{i}$ is the amount of the interested element in solution after the durability test, $A_{o}$ is the amount of the interested element in the sample; $S$ is the sample surface area of the waste form; and $t$ is the duration of the experiment [12].

Waste loading capacity is to accommodate a significant amount of waste in the host matrix to minimise volume for storage, transportation and disposal.

Radiation stability is to have a high tolerance to radiation effects from the decay of radioactive elements [12].

\subsection{Cement Waste Forms}

Cementation is the most practical and economical method for immobilization of nuclear wastes. The cement is prepared by mixing the waste and cement composition in ratio $1: 1$. Cement and cement compositions are intensively used in immobilisation of low level radioactive wastes and in special cases in immobilisation of medium level wastes. Cementation technique has some advantages like low cost, convenience of process, higher-level elimination than the other techniques and products of acceptable quality. Cement compositions with proper additives have been developed to improve structure of host matrix for waste immobilization. Disadvantages of cementation technique are weak mechanical durability of solidified waste products and high corrosion risk for long-term disposal in environmental conditions $[15,22]$.

\subsection{Vitrified Waste Forms}

Vitrification technique is one of the immobilization methods for high level radioactive waste. In this process, radioactive waste is converted to solid glass blocks for longterm storage and waste volume is reduced to $1 / 3$ of its original volume. The desired vitrified waste form is durable for thousands of year, poorly soluble in water, relatively cheap and easily workable and has appropriate mechanical properties [5, 12].

Borosilicate glasses have been commonly used for vitrification of high level wastes. Generally, it is thought that complex borosilicate glasses are relevant for long term immobilisation of radioactive waste products. It is more correct to say that borosilicate glass is the most suitable type of glass under current conditions, nevertheless, these glasses are not ideal for immobilisation because of several reasons [16]. One of the limitations of this type glass is the phase separation usually at microscopic scale. Phase separation on microscopic scale do not have an impact on the transparency and therefore invisible to the naked eye. Phase separation phenomenon in borosilicate glasses is often observed using scanning electron microscope (SEM) or small angle X-ray scattering (SAXS). This fact actually plays an important role in the glass production and its outstanding features $[5,16]$.

The reason for high chemical stability of borosilicate glasses is the diversity of highly decomposed silica and second phase. Main of second phase is alkaline borate which has weak chemical durability. In this way, it is obtained a glass having chemical durability close to that of pure silica. However, these two phases may be nested in some compositions. In this case, leaching of alkali metal and boron ions form host glass matrix is very easy. Therefore, the microstructure of different composition of borosilicate glasses needs to examined in sensitive applications such as the storage of nuclear waste in detail $[5,16]$.

Pure $\mathrm{B}_{2} \mathrm{O}_{3}$ glass consists of three $\left[\mathrm{BO}_{3}\right]$ groups containing boroxol rings and $\left[\mathrm{BO}_{3}\right]$ bridges combining them. $\left[\mathrm{BO}_{3}\right]$ group reacts with water easily; therefore, chemical durability of pure boron glass decreases. When alkaline oxides add to boron glasses, $\left[\mathrm{BO}_{3}\right]$ groups turn into $\left[\mathrm{BO}_{4}\right]$ groups and strengthen the glass lattice. Chemical durability of these glasses is higher than borosilicate glasses because of more stable $\left[\mathrm{BO}_{4}\right]$ groups. Addition of alkaline oxides over 30$40 \%$ mole to host glass causes to enter of oxygen into the structure and chemical durability of the glass decreases again. Though alkaline oxide-borate glasses have relatively high chemical stability, they are insufficient for any structural applications alone. However, addition of some oxides such as $\mathrm{Al}_{2} \mathrm{O}_{3}$ or $\mathrm{PbO}$ provides usability of the boron glasses in some applications [5].

Addition of $\mathrm{PbO}$ in suitable amounts to boron glass transforms $\left[\mathrm{BO}_{3}\right]$ groups to $\left[\mathrm{BO}_{4}\right]$ and the chemical stability increases for the host glass structure [18, 19]. Addition of $\mathrm{P}_{2} \mathrm{O}_{5}$ in low ratio significantly increases chemical stability in some boron glasses. Chemical durability of $\mathrm{SrTiO}_{3}$ alumina borate glasses with the addition of $9 \%$ mole $\mathrm{P}_{2} \mathrm{O}_{5}$ has increased up to 100 times at $90^{\circ} \mathrm{C}$. Fourier Transform Infrared Spectroscopy (FTIR) and Raman spectroscopy analysis has showed that increase in chemical durability was related to decrease in $\left[\mathrm{BO}_{3}\right]$ groups and increase in $\left[\mathrm{BO}_{4}\right]$ groups [20].

In another study, lead borate and lead bismuth borate glass have been compared for gamma radiation shielding applications. The mass attenuation coefficients of containing $20-70 \%$ additive glass have been investigated and obtained better radiation shielding properties comparing to barite concrete [21].

\section{The Development of New Materials for the Removal of Radioactive Waste}

The main immobilization techniques that can be applied commercially for low-level and high-level radioactive waste are cementation and vitrification, respectively. Even though vitrification enables substantial reduction of waste volume and works successful for waste safety, the method is highly complex and has high cost for initial investment. Current immobilization methods has some limitations, however they provide sufficient security. According to the new approaches, there is a need for creation of new waste forms, which can make for safety of nuclear waste management scenarios using geochemical stable materials.

Thermodynamically stable minerals may retain radionuclides in their structures because of their high isomorphic capacity. Different matrices such as glass, ceramic and glass-ceramic have been studied [24]. Ceramic waste forms can be used as immobilization matrices due to their analogous minerals durability in the long-term performance of geological conditions. Many natural 
analogues are potential ceramic structures for high-level radioactive waste. These are monazite $(\mathrm{Ce}, \mathrm{La}, \mathrm{Nd}, \mathrm{Th}) \mathrm{PO}_{4}$, zirconium, zirconium silicate $\left(\mathrm{ZrSiO}_{4}\right)$, zirconolite $\left(\mathrm{CaZr}_{\mathrm{x}} \operatorname{Ti}_{(3-\mathrm{x})} \mathrm{O}_{7}\right.$ where $\left.0.8<\mathrm{x}<1.35\right)$, apatite $\left(\mathrm{M}_{\mathrm{e} 10}\left(\mathrm{XO}_{4}\right) 6 \mathrm{Y}_{2}\right.$, where $\mathrm{M}_{\mathrm{e}}$ presents divalent cations, e.g: $\mathrm{Ca}^{2+}, \mathrm{Pb}^{2+}, \mathrm{Ba}^{2+}$; $\mathrm{XO}_{4}$ presents trivalent anions, e.g: $\mathrm{PO}_{4}, \mathrm{VO}_{4}, \mathrm{SiO}_{4}$ and $\mathrm{Y}$ presents monovalent anions, e.g: $\mathrm{F}^{-}, \mathrm{Cl}^{-}, \mathrm{OH}^{-}, \mathrm{Br}^{-}$and hollandite $\left(\mathrm{A}_{2} \mathrm{~B}_{8} \mathrm{O}_{16}\right)[16]$.

\subsection{Glass Composite Materials (GCM)}

Glass composite materials (GCM) are classified as completely amorphous glass waste forms and/or completely crystalline ceramic waste forms and can be produced in various ways. Such composite materials inherit both noncrystalline (glassy) and crystalline components. Depending on the intended application, the main component may be a crystalline phase, which plays a role as a binding agent in a glassy phase or alternatively glassy phase which is a particles of crystalline phase dispersed in the glass matrix. GCM can be used to immobilize long-lived radionuclides in the durable crystalline phase. The short-lived radionuclides are held in a less durable glassy phase. High tendency to crystallizing is common for glass-waste form. Recently, GCM are in great demand. This case is clearly seen in more difficult waste or improving acceptable durability of material $[12,25]$.

\subsection{Ceramic Materials}

Glass as a solidification material has some disadvantages for volatile radionuclides such as Tc, I, Cs etc. in HLW at the glass melting temperatures and solubility in glass matrix including some important radionuclides, such as actinides with long half-life.

Crystalline ceramic materials with a higher waste loading capacity than the glasses have advantageous for specific wastes. Ceramic waste forms including mineral analogues provide long-term durability for the nuclear wastes like a geological barrier. In addition, the use of hot press technology to ceramics prevents volatile losses in nuclear wastes. Radionuclides incorporate easily into crystalline phases in the ceramic structures and these crystalline phases allow high loadings of specific radionuclides [12, 23].

Ceramic structure has different coordination types for charge balance with radionuclide substitutions due to the complex composition of ceramic matrix. Specific crystalline phases are produced as a host for the different radionuclides in multiphase ceramic waste forms. Zirconolite, monazite, apatite, or sodium zirconium phosphate is single-phase ceramics to incorporate nearly all of the radionuclides into a single structure.

Several researchers have investigated in detail the use of ceramic materials for the immobilization of actinides in nuclear wastes [26-32]. Table 1 shows the leaching rate and waste loading capacity of some ceramic forms for different radionuclides. Most widely studied ceramics as waste form are titanate-based ceramics such as hollandite, perovskite or zirconolite [27, 32]. Synthetic mineral compositions such as monazite $(\mathrm{Ce}, \mathrm{Y}, \mathrm{La}, \mathrm{Th}) \mathrm{PO}_{4}$, apatite $\left(\mathrm{Ca}_{5} \mathrm{PO}_{4}\right)_{3}(\mathrm{~F}, \mathrm{Cl}, \mathrm{OH})$ etc. has been developed for disposal of high-level nuclear wastes due to their lower dissolution rate compared with borosilicate glass [26]. In recent, the candidate crystalline waste forms for the geological disposal of nuclear wastes are phosphate ceramics, which have a high stability, a high waste loading, a refractory nature and easy method of synthetic and their resistant to radiation damage [28-30].

\subsection{Glass-Ceramic Materials}

Glass-ceramics are produced by melting viscous glass materials and due to their high absorption capacities they are potential immobilisation materials for radioactive waste. Glass-ceramics are polycrystalline materials produced by controlled crystallization of amorphous glasses [12, 35]. A glass ceramic is a fine-grained mixture of glass and ceramic phases ideally derived from a homogeneous glass through a devitrification and can combine for immobilization of HLW with durable residual glass and ceramic phases [36]. Glass ceramics, which the formation of the desired phase by controlled crystallization is facilitated, gains improved mechanical and chemical properties comparing to main glass material.

Several crystal materials comprising silicate, glass ceramic, titanate $\left(\mathrm{CaTiOSiO}_{4}\right)$, zirconolite and zirconium dioxide $\left(\mathrm{ZrO}_{2}\right)$ were tested for sorption of long-lived actinides. Waste loading (50-70\%) is successfully applied in zirconolite and perovskite with high durability [25]. In particular, glass ceramics are ideal for producing ferroelectric ceramics. In addition, durability under high temperature, pressure and extreme environmental conditions make them attractive for many applications [37]. Despite difficulties in the preparation of glass ceramics due to low temperature sintering properties and fragility, $\mathrm{BaTiO}_{3}$ and $\mathrm{PbTiO}_{3}$ ceramics are being studied for many years considering their ferroelectric, piezoelectric and pyroelectric properties [38].

Physical properties of silicate-based glass-ceramics have found similar to that of commercial glass-ceramics and largely better than traditional natural stones. The elastic modulus and Vickers hardness have obtained as $70.2 \mathrm{GPa}$ and $6.35 \mathrm{GPa}$, compared to $86 \mathrm{GPa}$ and $5.88 \mathrm{GPa}$ for commercial neoparies glass ceramics or $82 \mathrm{GPa}$ and 4.22 $\mathrm{GPa}$ for natural stone marble or $60 \mathrm{GPa}$ and 5.59 for granite, respectively [9].

An important advantage of glass-ceramic materials compared to ceramic materials for immobilization of nuclear wastes is their better chemical durabilities. Table 2 shows the leaching rates of a glass-ceramic for different radionuclides.

Radiation stability on glass-ceramic forms has been investigated on glass-ceramics by researchers. The results indicate that radiation tolerance of these materials by irradiation with ions of various masses and energies of the damage created by the different sources of radiation is good for $\beta$-particles and $\gamma$-rays, but susceptible to amorphization under recoil nuclei effects $[12,39]$. 
Table 1. Leaching rate and waste loading capacity of some ceramic forms for different radionuclides

\begin{tabular}{|l|c|c|c|}
\hline Ceramic materials & Radionuclides & Leaching rate ${\mathbf{~} \mathbf{g m}^{-\mathbf{2}} \mathbf{d}^{-\mathbf{1}} \mathbf{)}}^{\text {References }}$ \\
\hline Zirconolite-based Titanate & $\mathrm{Pu}$ & $10^{-5}$ & {$[32]$} \\
\hline Zirconolite-based Titanate & $\mathrm{U}$ & $10^{-3}$ & {$[32]$} \\
\hline Zirconium phosphate & $\mathrm{Sr}$ & 5 & {$[33]$} \\
\hline Titanate & $\mathrm{U}$ & 7 & {$[27]$} \\
\hline Phosphate & $\mathrm{Th}$ & - & {$[28]$} \\
\hline Phosphate & $\mathrm{Th}$ & $10^{-5}$ & {$[30]$} \\
\hline Phosphate & $\mathrm{U}$ & $10^{-4}$ & {$[30]$} \\
\hline Ceramicrete & $\mathrm{Cs}$ & $3.04 \times 10^{-5}$ & {$[34]$} \\
\hline Zirconium phosphate & $\mathrm{Sr}$ & $<10^{-6}$ & {$[29]$} \\
\hline
\end{tabular}

Table 2. Leaching rates of a glass-ceramic forms for different radionuclides

\begin{tabular}{|l|c|c|c|}
\hline Ceramic materials & Radionuclides & Leaching rate $\left(\mathbf{g ~ c m}^{-2} \mathbf{d}^{-\mathbf{1}}\right)$ & References \\
\hline Ca doped $\mathrm{CePO}_{4}$ monazite & $\mathrm{Cs}$ & $2.1 \times 10^{-8}$ & {$[24]$} \\
\hline $\mathrm{Ca}$ doped $\mathrm{CePO}_{4}$ monazite & $\mathrm{U}$ & $2.4 \times 10^{-7}$ & {$[24]$} \\
\hline $\mathrm{Ca}$ doped $\mathrm{CePO}_{4}$ monazite & $\mathrm{Sr}$ & $1.1 \times 10^{-6}$ & {$[24]$} \\
\hline
\end{tabular}

\section{Conclusion}

Glass forms are recognized to be more technologically and ecologically feasible as compared to cement forms. Different glass compositions are used for immobilization of various radionuclides in HLW. Glass forms are not a suitable matrix due to its thermodynamic instability and its insufficient chemical durability and radiation resistance. From this point of view, the new solidification forms are considered as an alternative to glass forms.

Therefore, ceramic, glass-ceramic and composite forms as an alternative solidification form to glass forms can be used as host matrix for the immobilization of high-level radioactive wastes for long-term disposal in geologic storage. Chemical durability and physical properties of these forms are the most important parameters to immobilize the radionuclides in host matrix.

Chemical durability plays a vital role for the solidification materials to describe the mobility of the radionuclides from host matrix to eco-system. Chemical durability should be very high for the solidification materials for safety disposal of the waste form. Although the low cost of the immobilization process of the nuclear wastes is the most desirable property to choose the proper material for solidification, chemical durability and waste capacity of the solidification material should be stand in the forefront in the last decision.

Although many applications have released to immobilize of radionuclides in ceramic forms for understanding of chemical and physical durabilities and radiation-solid interaction in ceramics, these type researches for glassceramics are insufficient in detail to predict the effects of these parameters on host matrix for different radionuclides.

All solidification materials used for immobilization of nuclear wastes have different properties depending on their chemical compositions. Glass technology is well known process for thousands of years and has an advantage to produce with different compositions of raw materials.
Comparison with the glass materials, ceramics are traditional and well defined inorganic materials. However, their mechanical properties are lower than the glass likewise their low cost. Alternatively, glass-ceramics are a type of glass undergo controlled crystallisation. The mechanical properties and loaded waste capacities of glass-ceramics are superior to those of the parent glass. Usage of correct material for immobilization of nuclear waste depends on type of nuclear waste, availability of raw materials, feasibility and economic potential of the country

The development of host forms for nuclear waste management in repository conditions will require a fundamental understanding of effects of corrosion in different media, radiation-host matrix interaction, effect of time and temperature on micro and macro structural evaluation of the host and wasted forms. Therefore, different host matrix for radioactive wastes from nuclear industry should be systematically studied over the widest range of conditions using new compositions and techniques.

\section{References}

[1] M. Benedict, T.H. Pigford and H.W. Levi, "Nuclear Chemical Engineering", McGraw-Hill Book Company, Second Edition, 1981, USA.

[2] F. Cattant, D. Crusset and D. Feron, "Corrosion Issues in Nuclear Industry Today”, Materials Today, 11(10) (2008) 32-37.

[3] L. Cecille, "New Separation Chemistry Techniques for Radioactive Waste and other Specific Applications", Elsevier Applied Science, 1991, London and New York.

[4] J.H. Saling and A.W. Fentiman, "Radioactive Waste Management", Second Edition, Taylor\&Francis, 2002, NewYork, London.

[5] J.E. Shelby, "Introduction to Glass Science and Technology", Second Edition, New York State College of Ceramics at Alfred University School of Engineering, 
Alfred, NY, USA, The Royal Society of Chemistry, 2005.

[6] K. Raj, K.K. Prasad and N.K. Bansal, "Radioactive Waste Management Practise in India", Nuclear Engineering and Design, 236: p.914-930, 2006.

[7] International Atomic Energy Agency (IAEA), "Nuclear Energy Series, Policies and Strategies for Radioactive Waste Management, No: NW-G-1.1, International Atomic Energy Agency, Vienna, 2009a.

[8] International Atomic Energy Agency (IAEA), "Safety Standards Series, Predisposal Management of Radioactive Waste", No: G SR Part 5, International Atomic Energy Agency, Vienna, 2009b.

[9] E. Bernardo, M. Varrasso, F. Cadamuro and S. Hreglich, "Vitrification of Wastes and Preparation of Chemically Stable Sintered Glass-Ceramic Products", Journal of Non-Crystalline Solids, 352: p. 4017-4023, 2006.

[10] European Commission, "Geological Disposal of Radioactive Wastes Produced by Nuclear Power, Community Research", Editor: Neil Chapman, Belgium, 2004.

[11] F. Cattant, D. Crusset and D. Féron, "Corrosion issues in nuclear industry today", Materials Today, 11(10): p.32-37, 2008.

[12] C.M. Jantzen, W.E. Lee and M.I. Ojovan, "Radioactive Waste (RAW) Conditioning, Immobilization, and Encapsulation Processes and Technologies: Overview and Advances, Radioactive Waste Management and Contaminated Site Clean-up”, p.171-272, 2013.

[13] M. I. Ojovan and William E. Lee, "An Introduction to Nuclear Waste Immobilisation", 2nd Edition, Elsevier, 2014.

[14] C. Bayliss and K. Langley, "Nuclear Decommissioning, Waste Management, and Environmental Site Remediation”, First Edition, Elsevier, pp.330, 2003.

[15] L. Junfeng, W. Jianlong, "Advances in cement solidification technology for waste radioactive ion exchange resins: A review", Journal of Hazardous Materials B, 135: p. 443-448, 2006.

[16] C. Erdogan, M. Bengisu, S. Akyil Erenturk, "Chemical Durability and Structural Analysis of $\mathrm{PbO}-\mathrm{B}_{2} \mathrm{O}_{3}$ Glasses and Testing for Simulated Radioactive Wastes", Journal of Nuclear Materials, 445: p. 154164, 2014.

[17] W. Vogel, "Chemistry of Glass", American Ceramic Society, Columbus, Ohio, 1985.

[18] Y. Cheng, H. Xiao and W. Guo, "Structure and Crystallization Kinetics of $\mathrm{PbO}-\mathrm{B}_{2} \mathrm{O}_{3}$ Glasses", Ceramic International, 33: p. 1341-1347, 2007.

[19] Y. Saddeek, "Structural and Acoustical Studies of Lead Sodium Borate Glasses", Journal of Alloys and Compounds, 467(1): p. 14-21, 2008.
[20] M. Bengisu, R.K. Brow, E. Yilmaz, A. MogusMilankovic and S.T. Reis, "Aluminoborate and Aluminoborosilicate Glasses with High Chemical Durability and the Effect of $\mathrm{P}_{2} \mathrm{O}_{5}$ Additions on the Properties", Journal of Non-Crystalline Solids, 352: p. 3668-3676, 2006.

[21] N. Singh, K.J. Singh, K. Singh and H. Singh, "Comparative Study of Lead Borate and Bismuth Lead Borate Glass Systems as Gamma Radiation Shielding Materials", Nuclear Instruments and Methods in Physic Researches B, 225: p.305-309, 2004.

[22] M.I. Ojovan and W.E. Lee, "An Introduction to Nuclear Waste Immobilisation", 2nd Edition, Elsevier Insight, 376: 2013.

[23] S.V. Stefanovsky, S.V. Yudintsev, R. Giere and G.R. Lumpkin, "Nuclear waste forms", in Energy, Waste, and the Environment: A Geochemical Perspective, R. Giere, P. Stille (eds), Geological Society, London, Special Publications, 236: p.37-63, 2004.

[24] R. Asuvathraman, K. Joseph, R. Raja Madhavan, R. Sudha, R. Krishna Prabhu and K.V. Govindan Kutty, "A versatile monazite-IPG glass-ceramic waste form with simulated HLW: Synthesis and characterization", Journal of the European Ceramic Society, 35: p.42334239, 2015.

[25] W.E. Lee, M.I. Ojovan, M.C. Stennett and N.C. Hyatt, "Immobilisation of Radioactive Waste in Glasses, Glass Composite Materials and Ceramics", Advances in Applied Ceramics, 105(1): p. 3-12, 2006.

[26] L. Bois, M.J. Guittet, F. Carrot, P. Trocellier and M. Gautier-Soyer, "Preliminary Results on the Leaching Process of Phosphate Ceramics, Potential Hosts for Actinide Immobilization", Journal of Nuclear Materials, 297: p.129-137, 2001.

[27] M.L. Carter, H. Li, Y. Zhang, E.R. Vance and D.R.G. Mitchell, "Titanate Ceramics for Immobilisation of Uranium-Rich Radioactive Wastes arising from ${ }^{99} \mathrm{Mo}$ Production", Journal of Nuclear Materials, 384: p.322326, 2009.

[28] E. Du Fou de Kerdaniel, N. Clavier, N. Dacheux, O. Terra and R. Podor, "Actinide Solubility-Controlling Phases during the Dissolution of Phosphate Ceramics", Journal of Nuclear Materials, 362: p.451-458, 2007.

[29] S. Nakayama and K. Itoh, "Immobilization of Strontium by Crystalline Zirconium Phosphate", Journal of the European Ceramic Society, 23: p.10471052, 2003.

[30] O. Terra, N. Dacheux, F. Audubert and R. Podor, "Immobilization of Tetravalent Actinides in Phosphate Ceramics", Journal of Nuclear Materials, 352: p.224232, 2006.

[31] W.J. Weber, R.C. Ewing, C.R.A. Catlow, T. Diaz de la Rubia, L.W. Hobbs, C. Kinoshita, Hj. Matzke, A.T. Motta, M. Nastasi, E.K.H. Salje, E.R. Vance and S.J. Zinkle, "Radiation Effects in Crystalline Ceramics for 
the Immobilization of High-Level Nuclear Waste and Plutonium", Journal of Materials Research, 13(6): p.1434-1484, 1998.

[32] Y. Zhang, M.W.A. Stewart, H. Li, M.L. Carter, E.R. Vance and S. Moricca, "Zirconolite-rich Titanate Ceramics for Immobilisation of Actinides-Waste Form/HIP can Interactions and Chemical Durability", Journal of Nuclear Materials, 395: p. 69-74, 2009.

[33] V. Pet'kov, E. Asabina, V. Loshkarev and M. Sukhanov, "Systematic investigation of the strontium zirconium phosphate ceramic form for nuclear waste immobilization", Journal of Nuclear Materials, 471: p.122-128, 2016.

[34] A.S. Wagh, S.Y. Sayenko, V.A. Shkuropatenko, R.V. Tarasov, M.P. Dykiy, Y.O. Svitlychniy, V.D. Virych and E.A. Ulybkin, "Experimental Study on Cesium Immobilization in Struvite Structures", Journal of Hazardous Materials, 302: p.241-249, 2016.

[35] M. Kim and J. Heo, "Calcium-Borosilicate GlassCeramics Wasteforms to Immobilize Rare-Earth Oxide Wastes from Pyro-Processing", Journal of Nuclear Materials, 467: p. 224-228, 2015.
[36] W.J. Weber, A. Navrotsky, S. Stefanovsky, E.R. Vance and E. Vernaz, "Materials Science of High-Level Nuclear Waste Immobilization", MRS Bulletin, Volume 34: p.46-53, 2009.

[37] S. Jakkula and V. Deshpande, "Effect of $\mathrm{MgO}$ Addition on the Properties of $\mathrm{PbO}-\mathrm{TiO}_{2}-\mathrm{B}_{2} \mathrm{O}_{3}$ Glass and Glass-Ceramics", Ceramics International, 39: p.15-18, 2013.

[38] S. Golezardi, V.K. Marghussian, A. Beitollahi and S.M. Mirkazemi, "Crystallization Behavior, Microstructure and Dielectric Properties of Lead Titanate Glass Ceramics in the Presence of $\mathrm{Bi}_{2} \mathrm{O}_{3}$ as a Nucleating Agent", Journal of the European Ceramic Society, 30: p.1453-1460, 2010.

[39] M. Tang, A. Kossoy, G. Jarvinen, J. Crum, L. Turo, B. Riley, K. Brinkman, K. Fox, J. Amoroso, and J. Marra, "Radiation Stability Test on Multiphase Glass Ceramic and Crystalline Ceramic Waste Forms", Nuclear Instruments and Methods in Physics Research B, 326: p.293-297, 2014. 